\title{
Analisa Fraksi Gasoil Berdasarkan Uji Sifat Fisika
}

\author{
Yully mulyani,Dian Afriana, \& Indah Dhamayanthie \\ Teknik kimia, Akademi Minyak Dan Gas Balongan Indramayu \\ yullymulyani@gmail.com
}

\begin{abstract}
Abstrak
Gasoil merupakan minyak yang digunakan sebagai bahan bakar diesel, terutama distilat minyak bumi menengah direntang didih dan viskositas antara minyak tanah dan minyak pelumas. Menurut American Standart for Testing and Material (ASTM), uji sifat fisika minyak bumi diperlukan untuk mendapatkan data dalam menangani pengangkutan, penyimpanan, penimbunan, pengolahan dan pemasaran. Parameter pengujian sifat fisika, yaitu specific gravity at $60 / 60{ }^{\circ} \mathrm{F}$ dengan metode ASTMD.4052, titik tuang (pour point) dengan metode ASTMD.97, kekentalan atau viscosity diuji dengan metode ASTMD.445-11a didapat viscosity at $100{ }^{\circ} \mathrm{F}$, viscosity at $122{ }^{\circ} \mathrm{F}$, viscosity at $140{ }^{\circ} \mathrm{F}$, flash point dengan metode ASTMD.93, Aniline point dengan metode ASTMD.611, untuk menentukan warna dalam fraksi perlu digunakan ASTM Colour dengan metode ASTMD.1500. hasil pengujian yang didapatkan specific gravity at $60 / 60{ }^{\circ} \mathrm{F}$ sampel 168 termasuk klasifikasi heavy crude oil, sampel 288 termasuk dalam klasifikasi light crude oil dan sampel 462 termasuk dalam klasifikasi medium crude oil.
\end{abstract}

Kata kunci : ASTM, Crude oil, Gasoil, Sifat Fisika

\section{PENDAHULUAN}

Pengolahan minyak bumi yang menghasilkan produk fraksi minyak lumas yang lebih murni dapat memberikan peningkatan ketahanan beberapa sifat minyak pelumas. Mulai tahun 1920 dihasilkan produk pelumas yang baik dengan menggunakan vacuum distillation dan beberapa fraksinya dikombinasikan dengan sabun untuk mendapat gemuk. Beberapa aditif untuk meningkatkan performa base oil (minyak lumas dasar) dari minyak bumi telah dikembangkan dan penggunaannya meningkat ditahun 1930. Pada awalnya hanya sekedar untuk meningkatkan sifat-sifat fisik pelumas, kemampuan mengontrol kerusakan minyak itu sendiri menjadi semakin penting, karena pemakaian pada pembakaran.

Perkembangan teknologi laboratorium harus memenuhi segala permintaan yang dituntut untuk mendukung operasi kilang minyak maupun aplikasi produk-produk dimasyarakat. Keadaan ini harus didukung dengan perkembangan tentang metode, sarana, peralatan, tenaga laboratoriumnya. Bermacam macam metode yang telah digunakan dilaboratorium diantaranya telah menjadi metode standard yang dipakai dalam kegiatan pengolahan dan bahkan perdangangan miyak.

Berdasarkan latar belakang diatas maka tujuan dari penulisan makalah ini adalah menganalisa sifat fisika dari gasoil. Dengan menggunakan beberapa parameter yaitu specific gravity at $60 / 60^{\circ} \mathrm{F}$ dengan metode ASTM D.4052, API gravity at $60^{\circ} \mathrm{F}$ dengan metode by Conversion, Calculated Cetane Index ini yang merupakan perhitungan yang terdapat dalam Gasoil, Aniline Point dengan menggunakan Ruang Asam, Titik tuang (pour point) dengan metode ASTM D-97, Flash Point "PMCC" dengan metode ASTMD-93, ASTM Colour dengan metode ASTMD-1500, Kinematic Viscosity at $100^{\circ} \mathrm{F}, 122^{\circ} \mathrm{F}$, dan $140^{\circ} \mathrm{F}$ dengan metode ASTMD-445.

\section{TINJAUAN PUSTAKA}

\subsection{Spesifikasi dan Klasifikasi Minyak Pelumas}

Gasoil Minyak hidrokarbon yang digunakan sebagai bahan bakar minyak, terutama distilat minyak bumi menengah direntang didih dan viskositas antara minyak tanah dan minyak pelumas. Berbeda dengan bahan bakar, persyaratan minyak pelumas yang digunakan umumnya disesuaikan oleh pabrik pembuatan mesin, sesuai dengan tugas mesin yang bersangkutan. Mengenai mutu minyak pelumas mesin, digunakan dasar klasifikasi yang umum berlaku,[1]

\subsubsection{Klasifikasi Minyak Karter Menurut SAE}

Pada tahun 1911, Society of Automotive Engineers untuk pertama kalinya membagi minyak pelumas karter ke dalam bilangan viskositas SAE (SAE Viscosity Number) yang di dasarkan kepada daerah viskositas minyak pelumas pada suhu tertentu. Minyak pelumas karter 10W-50 minyak pelumas ini dapat digunakan untuk melumasi mesin yang memerlukan minyak dari SAE 10W sampai SAE 50W. Di samping mencegah keausan mesin,[1]

\subsubsection{Klasifikasi minyak karter menurut API}


Pada tahun 1945, American Petroleum Institute (API), membagi minyak karter menjadi 3 jenis regular, premium, dan heavy duty. Karena klasifikasi ini belum mencukupi, maka pada tahun 1952 API mengadakan klasifikasi minyak pelumas karter baru, yang didasarkan kepada kondisi pelayanan (service conditions). minyak pelumas karter dibagi menjadi dua kelompok besar, minyak pelumas untuk mesin motor bensin, yang diberi kode huruf M,dan minyak pelumas untuk mesin motor diesel, yaitu diberi kode huruf D. [1]

\subsubsection{Klasifikasi lain}

Selain klasifikasi dan spesifikasi diatas, masih terdapat beberapa klasifikasi atau spesifikasi minyak pelumas lainnya seperti yang dikeluarkan oleh General Motor, Caterpillar dan Mercedes Benz. [1]

\subsection{Sifat-sifat Minyak Pelumas}

Sifat penting minyak pelumas ialah sifat alir dan kecocokannya sebagai minyak pelumas untuk kondisi pemakaian yang berbeda-beda. Sifat alir minyak pelumas.

\subsubsection{Viskositas}

Minyak pelumas dapat ditentukkan dengan viskosimeter pipet (ASTM D 445-88). Viskosimeter Saybolt yang telah lama digunakan sebagai alat uji baku viskositas

\subsubsection{Indeks viskositas}

Indeks yang berhubungan dengan kecepatan perubahan viskositas dengan suhu. Indeks ini ditemukan oleh Dean dan Davis dari Standard Oil Development Company pada tahun 1932. Berdasarkan viskositas minyak pembanding dan minyak contoh pada suhu $40^{\circ} \mathrm{C}$ dan $100^{\circ} \mathrm{C}$, maka indeks viskositas minyak contoh dapat di tentukan dengan persamaan,

\section{Indeks viskositas $=(\mathrm{L}-\mathrm{U}) /(\mathrm{L}-\mathrm{H}) \times 100$}

Dimana $\mathrm{L}$ dan $\mathrm{H}$ adalah viskositas minyak referensi yang mempunyai indeks viskositas 0 dan 100 (keduanya mempunyai viskositas yang sama pada $100^{\circ} \mathrm{C}$ ) dan $\mathrm{U}$ adalah viskositas contoh, semuanya pada suhu $40^{\circ} \mathrm{C}$

\subsubsection{Titik Tuang}

Suhu terendah dimana minyak pelumas masih dapat mengalir, merupakan sifat minyak pelumas yang penting apabila digunakan di tempat-tempat yang berhawa dingin. Untuk Indonesia dimana suhu rata-rata sepanjang tahun relatif tinggi maka kiranya tidak ada masalah untuk sifat ini.

\subsubsection{Ketahanan Oksidasi}

Uji ketahanan oksidasi minyak pelumas, dilakukan dengan jalan memanaskan minyak pelumas dan udara atau oksigen pada suhu $200^{\circ} \mathrm{F}$ sampai terbentuk lumpur, banyaknya lumpur yang terbentuk merupakan ukuran ketahanan minyak pelumas.[2]

\subsubsection{Daya dukung beban}

Kemampuan lapisan minyak pelumas tipis untuk tidak putus karena adanya beban berat tergantung kepada suhu, beban, kecepatan, kekasaran permukaan dan komposisi permukaan logam yang dilumasi. Uji daya dukung beban dilakukan dengan menaikkan beban pada komponen mesin yang dilumasi yang diputar dengan kecepatan perputaran tertentu. [1]

\subsection{Karakteristik Gasoil}

Karakteristik minyak bumi adalah batasan maksimum atau minimum suatu parameter minyak bumi yang dikehendaki sebagai umpan proses pengolahan. Karakteristik minyak bumi mencakup sifat-sifat fisika, sifat Kimia, sifat optikal, sifat thermal, sifat kelistrikan dan lain-lain. Sifat fisika minyak bumi untuk mendapatkan informasi dalam menangani pengangkutan, penyimpanan, penimbunan, pengolahan dan pemasaran.[2]

\subsubsection{Specific Gravity (ASTMD-4052)}

Specific gravity adalah Berat jenis. Density adalah Massa zat cair per satuan volume pada $15{ }^{\circ} \mathrm{C}$ dan $101,325 \mathrm{kPa}$ dengan satuan standar pengukuran dalam kilogram per meter kubik. Density lebih kecil dari Specific gravity. Kekentalan Specific gravity dan density berbeda.[3]

\subsubsection{API Gravity}

Density rendah menunjukkan kandungan parafin besar, sebaliknya density tinggi menunjukkan kandungan aromat tinggi. Hubungan antara antara API Gravity dan Carbon Residu yaitu semakin tinggi API Gravity, maka semakin rendah harga Carbon Residu dan sebaliknya. Hubungan antara API Gravity dan Viskositas adalah semakin tinggi API Gravity, maka semakin kecil viskositas dan sebaliknya.[1]

Hubungan antara API Gravity dan Kandungan Aspalthenes adalah semakin tinggi API Gravity, maka semakin kecil Kandungan Aspalthenes dan sebaliknya.

Persamaan 2 .

$$
\mathrm{API}=\frac{141.5}{\mathrm{SG}}-131.5
$$
gravity.[4]

Hubungan antara API gravity dan Specific gravity adalah Semakin besar Specific gravity maka semakin rendah API 


\subsubsection{Calculated Cetane Index}

Fungsi Calculated Cetane Index adalah untuk angka anti ketuk di ASTM-D976. Perhitungan indeks setana tidak dapat menjelaskan aditif improver cetane dan karena itu tidak mengukur jumlah total cetane untuk bahan bakar diesel additized. Pelumas mempunyai kemampuan yang berbedabeda untuk menahan ketukan. Tahanan ketukan pelumas disebut kualitas anti ketuk (antiknock quality) dan diukur dengan angka cetane. Jika memiliki cetane number tinggi, ini berarti jangka waktu penundaan relatif singkat. Dalam hal ini, jangka waktu penundaan singkat memungkinkan diesel untuk membakar lebih lengkap. [1]

\subsubsection{Aniline Point (ASTM D-611)}

Titik Anilin digunakan untuk pengamatan karakteristik hidrokarbon murni dan dalam analisa campuran hidrokarbon. Hidrokarbon aromatic ditunjukkan dengan titik nilai anilin terendah, sementara paraffin yang tertinggi. Sikloparafin dan Olefin ditunjukkan dengan nilai diantara paraffin dan aromatik. Dalam deret homolog titik aniline meningkat dengan meningkatnya bobot molekul.

\subsubsection{Titik Tuang atau Pour Point (ASTM D 97)}

Pour point atau titik tuang adalah suhu terendah dimana sampel masih bisa mengalir, harga temperatur yang menyebabkan minyak bumi yang didinginkan mengalami perubahan sifat dari bisa menjadi tidak bisa dituangkan atau sebaliknya. Makin rendah titik tuang, berarti kadar parafin makin rendah sedangkan kadar aromatnya makin tinggi. Persamaan

$$
\text { Pour Point }=\text { Temperatur }+3
$$

\subsubsection{Flash Point "PMCC" Metode (ASTMD-93)}

Flash point atau titik nyala adalah suhu terendah dimana uap minyak bumi dan produknya dalam campurannya dengan udara akan menyala kalau dikenai nyala uji pada kondisi tertentu. Flash point "PMCC" ini digunakan untuk menentukan titik nyala produk minyak bumi yang memiliki titik nyala antara 780C sampai 2000C. semakin banyak komposisi fraksi ringan dalam sampel maka suhu flash point akan semakin rendah karena fraksi ringan memiliki tekanan uap yang

\section{Barometer terkoreksi = barometer + FK barometer}

Flash Point $=$ Temperatur terkoreksi $+0,033-$ Baro terkoreksi

\subsubsection{ASTM Colour (ASTMD 1500)}

Penentuan warna adalah membandingkan warna standar dengan warna contoh uji. Metode ini melaporkan hasil yang dinyatakan sebagai "Warna ASTM" karena warna dapat dipakai sebagai petunjuk kesempurnaan dalam pengolahan, transportasi maupun dalam hal penyimpanan. Penentuaan warna produk minyak bumi terutama digunakan untuk tujuan control produksi dan merupakan suatu karakteristik mutu yang penting karena warna dengan mudah dapat diamati oleh pengguna produk.[5]

\subsubsection{Kinematic Viscosity (ASTMD-445)}

Pengukuran kinematic viscosity adalah salah satu pengukuran ciri ciri fisik yang penting dari minyak pelumas, kinematic Viscosity berhubungan dengan kekentalan dan merupakan persyaratan yang ditetapkan SAE atau ISO dalam spesifikasi teknik minyak pelumas, untuk kendaraan bermotor dan industry. Pengukuran viskositas bertujuan mengetahui kekentalan minyak pada suhu tertentu sehingga minyak dapat dialirkan pada suhu tersebut, terutama pada sistem pemompaan minyak diesel \& minyak pelumas. semakin ringan minyak bumi, maka makin kecil viskositanya, atau sebaliknya. Viskositas yang dicatat adalah lama waktu pengaliran minyak dalam wadah dengan volume tertentu melalui lubang (orifice) tertentu pd suhu tertentu. Angka viskositas dipakai sebagai dasar untuk menentukan angka indeks viskositas, menggambarkan perubahan viskositas akibat perubahan suhu. Jika indek viskositas tinggi, maka viskositasnya relatif tidak berubah terhadap suhu, jika rendah berarti viskositas sangat dipengaruhi suhu.

\section{METODE PENELITIAN}

\section{PENGUJIAN SIFAT FISIKA GASOIL}

3.1 Specific gravity at 60/60 ${ }^{\circ}$ F Metode (ASTM D.4052) dan API Gravity at 60/60 F (By Conversion)

Metode uji ini untuk menentukkan nilai densitas, gravitasi spesifik atau gravitas API fraksi gasoil yang berupa cairan. Sampel gasoil diinjeksikan menggunakan injector kedalam lubang sampel hingga full, jangan sampai adanya gelembung atau rongga pada saluran sampel, memulai mendeteksi SG menggunakan Gambar 1. hingga nilai SG muncul.

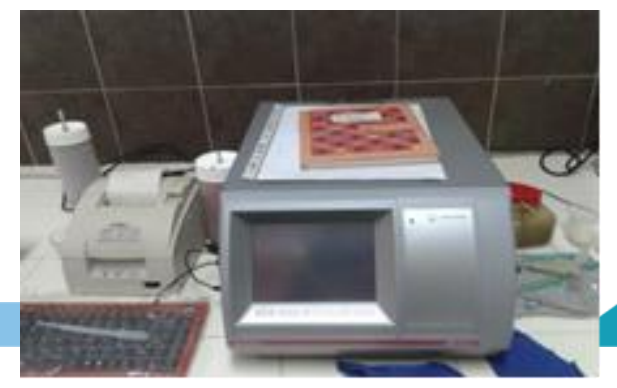


Gambar 1. Density meter

Tabel 1. Data Sampel Sifat fisik fraksi gasoil

\begin{tabular}{|c|c|c|c|c|c|}
\hline sampel & API grafity & SG at 6 6 F & Pour point C & $\begin{array}{c}\text { Sulfur content } \\
\text { \%wt }\end{array}$ & Wax content \%wt \\
\hline 168 & 17,3 & 0,951 & 0 & 0,233 & 0 \\
\hline 288 & 66,1 & 0,7162 & -36 & 0,02 & 0,23 \\
\hline 462 & 32,2 & 0,8644 & 27 & 0,378 & 24,94 \\
\hline
\end{tabular}

Data hasil SG Metode ASTM D.4052 di laboratorium distilasi dengan potongan $180-350{ }^{\circ} \mathrm{C}$ dan $250-350^{\circ} \mathrm{C}$

Tabel 2. Data Pengamatan uji Spesific gravity sampel 168

\begin{tabular}{|c|c|c|c|c|c|}
\hline Cut ${ }^{\circ} \mathbf{C}$ & $\begin{array}{c}\text { Refractive } \\
\text { Index }\end{array}$ & $\begin{array}{c}\text { Rata- } \\
\text { rata }\end{array}$ & $\begin{array}{c}\text { Density } \\
\mathbf{g r} / \mathbf{c m}^{3}\end{array}$ & $\begin{array}{c}\text { Rata-rata } \\
\mathbf{g r} / \mathbf{c m}^{3}\end{array}$ & $\begin{array}{c}\text { Specific } \\
\text { Gravity }\end{array}$ \\
\hline $180-350^{\circ} \mathrm{C}$ & 1,4968 & 1,4968 & 0,9016 & 0,9000 & 0,9009 \\
\hline & 1,4969 & & 0,9018 & & \\
\hline $250-350^{\circ} \mathrm{C}$ & 1,5206 & 1,5206 & 0,9147 & 0,9336 & 0,9345 \\
\hline & 1,5206 & & 0,9149 & & \\
\hline
\end{tabular}

Dilakukan hal yang sama untuk pengujian sampel 288 dan 462. Dan untuk mencari nilai dari API Gravity 60/60 ${ }^{\circ} \mathrm{F}$ dengan memakai Persamaan 2. Dengan potongan suhu $180-350{ }^{\circ} \mathrm{C}$ dan $250-350{ }^{\circ} \mathrm{C}$.

\subsection{Calculated Cetane Index}

Untuk menentukan mutu atau kualitas fraksi gasoil di suatu perusahaan. didapatkan data Medium boiling point MBP 276 ${ }^{\circ} \mathrm{C}$ density $0,9017 \mathrm{gr} / \mathrm{cm}^{3}$

\subsection{Aniline Point Metode (ASTMD-611)}

Sejumlah volume aniline dan contoh, atau aniline dan contoh ditambah n-heptane, Alat dan bahan aniline point ASTM976, Pipet Tetes, corong dan gelas, sampel fraksi gasoil, cairan Aniline, Aceton. Prosedur memanaskan alat Aniline point ASTM-976, mengambil 10ml aniline cair dan memasukkan kedalam mesin Aniline Point ASTM-976, Men-settingheater control dengan 50, light control dari penuh 100 turun menjadi 70-80 ditempatkan dalam tabung dan diaduk secara mekanik dengan putaran 30 - 40. sampel fraksi Gasoil dan cairan Aniline bercampur,Campuran dipanaskan dengan pemanasan yang terkontrol sampai kedua fase dapat tercampur seperti Gambar 2. Campuran tersebut kemudian didinginkan dengan kecepatan yang terkontrol. Menunggu sampai lampu yang berwarna merah berubah menjadi warna hijau, Temperatur pada saat kedua fase terpisah dicatat sebagai titik aniline atau titik aniline campuran.

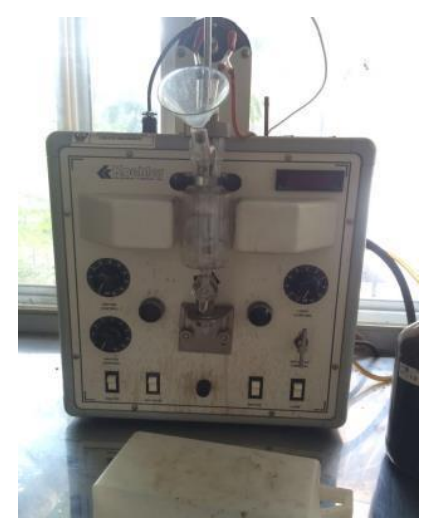

Tabel 3. Data Pengamatan Uii Aniline Point Sampel 168

\begin{tabular}{|c|c|c|c|c|c|}
\hline No. & $\begin{array}{c}\text { Temperatur } \\
\text { Pengamatan }\end{array}$ & Foreksi & Terkoreksi & $\mathbf{X}$ & Hasil \\
\hline $168 \mathrm{E}$ & $46,0^{\circ} \mathrm{C}$ & $-1,6$ & $44,4^{\circ} \mathrm{C}$ & $44,4^{\circ} \mathrm{C}$ & $44,4^{\circ} \mathrm{C}$ \\
\hline & $46,0^{\circ} \mathrm{C}$ & $-1,6$ & $44,4^{\circ} \mathrm{C}$ & & \\
\hline $168 \mathrm{~F}$ & $44,9^{\circ} \mathrm{C}$ & $-1,6$ & $43,3^{\circ} \mathrm{C}$ & $43,3^{\circ} \mathrm{C}$ & $43,3^{\circ} \mathrm{C}$ \\
\hline & $44,9^{\circ} \mathrm{C}$ & $-1,6$ & $43,3^{\circ} \mathrm{C}$ & & \\
\hline
\end{tabular}

Gambar 2. Aniline Point

\subsection{Pour Point Metode (ASTM D-97)}

Minyak mempunyai perlakuan yang berbeda-beda antara jenis yang satu dengan jenis yang lainnya. Dengan mengetahui titik tuang, maka dapat diketahui perlakuan yang harus dilakukan terhadap minyak tersebut. Alat dan bahan gelas kimia, 
thermometer batang, water bath, tube, penutup gabus, sampel fraksi gasoil Prosedur percobaanya, Menyalakan alat pour point Gambar 3 Ada 4 tahap pendinginan. Kemudian menyalakan bak pemanas, fungsi untuk memanaskan sampel sampai suhu 50 oC, memasukkan sampel ke dalam tube, memasukkan tube ke alat pour point dari suhu awal, melakukan pengecekan pada saat penurunan thermometer $-3 \mathrm{oC}$, kegiatan ini dilakukan apakah sampel dalam tube sudah membeku atau belum, setelah itu mengambil data. Potongan suhu $180-350^{\circ} \mathrm{C}$ Potongan $180-350^{\circ} \mathrm{C}$ Pour Point (ASTMD-97)

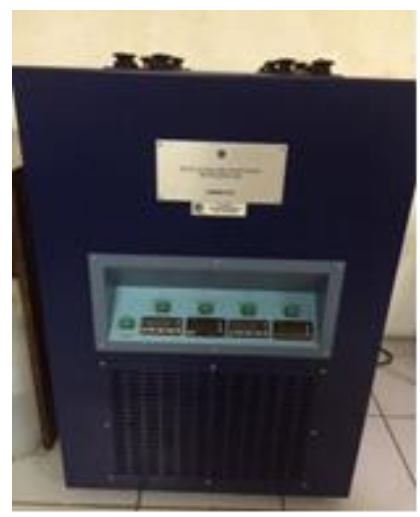

Gambar 3. Pour Point

\subsection{Flash Point "PMCC” Metode (ASTMD-93)}

Titik nyala dari volatile bahan adalah yang terendah suhu dimana uap cairan akan menyala. pengukuran titik nyala membutuhkan sumber pengapian. Pada titik nyala, uap dapat berhenti untuk membakar ketika sumber pengapian mati. suhu autosulutan (yang tidak memerlukan sumber pengapian) atau dengan titik api (suhu dimana uap yang terus membakar setelah dinyalakan). Baik titik nyala atau titik api tergantung pada suhu sumber pengapian, yang jauh lebih tinggi.

Alat dan bahan, flash point"PMCC" (IP.17 ), thermometerbatang dan sumber nyala. Prosedur memasukkan sampel ke cupflash point sampai batas yang ditentukan, menaruh sampel didalam ruangan suhu kamar. Memasangkan thermometer batang di cup yang berisi sampel memasukkan cup ke dalam flash point Gambar 4, menyalakan api pada alat pematik flashpoint untuk mengecek sampel sampai terjadi flash, memutar ujung pada cup, kegiatan ini dilakukan agar sampel didalam cup mencair.

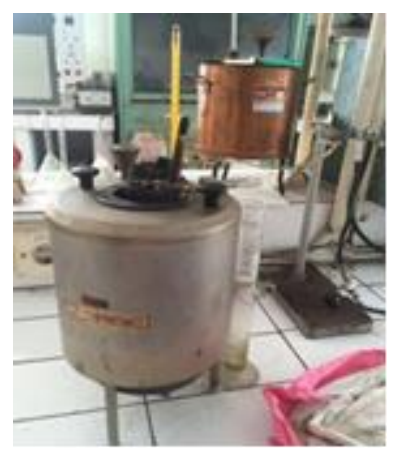

Gambar 4. Flash Point "PMCC"

Data yang diambil fraksi gasoil potongan $180-350^{\circ} \mathrm{C}$ nomer sampel 168 , temperature $90^{\circ} \mathrm{C}$ barometer $751 \mathrm{mmhg}$, factor terkoreksi 0. Fraksi gasoil potongan $250-350^{\circ} \mathrm{C}$ nomer sampel 168, temperatur $126^{\circ} \mathrm{C}$ barometer $751 \mathrm{mmhg}$, factor terkoreksi 0. Dihitung menggunakan Persamaan (4) dan Persamaan (5) Dilakukan hal yang sama untuk pengujian sampel 288 dan 462.

\subsection{ASTM Colour ASTM D-1500}

Penentuan warna adalah membandingkan warna standar dengan warna contoh uji, menggunakan sumber cahaya standar, contoh uji cair ditempatkan ke dalam tabung uji, dan di bandingkan dengan warna standar. Nilai skalanya berkisar antara 0,5 sampai dengan 8,0. Bila tidak diperoleh warna yang tepat sama dan warna contoh berada diantara dua warna standar, laporkan warna yang tertinggi dari kedua warna standar tersebut. Alat dan bahan Calorimetri, tabung uji, tree field, sampel gasoil 168. Prosedur memasukkan sampel ke dalam gelas ukur $50 \mathrm{~mm}$. Memasukkan aquades atau air deionisasi dalam gelas ukur yang sudah ada sampelnya pada alat calorimeter, Menghidupkan sumber cahaya, mengamati dan membandingkan warna sampel dengan skala warna standar. 


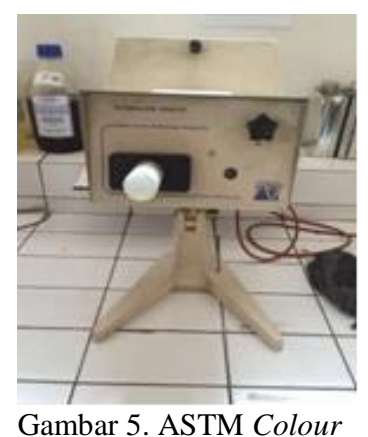

\subsection{Kinematic Viscosity (ASTM D. 445-11a)}

Viskositas kinematika adalah hasil perkalian waktu alir terukur dengan konstanta kalibrasi viskometer. Penentuan kinematic viscosity diketahui, dynamic viscosity dapat diperoleh dengan mengalikan kinematic dengan density. prosedur percobaan nya sbg berikut. Alat dan bahan kinematic viscocity bath VB-M6P ASTM-445 $100^{\circ} \mathrm{F}$ gambar 5, Termometer batang, kapiler $125 \mathrm{ml}$ ASTM-IP, stopwatch, dan sampel fraksi

gasoil. Prosedur, menyaring sampel 168 ke dalam gelas kimia, mempersiapkan bak pemanas dengan suhu $100 \mathrm{~F}, 122 \mathrm{~F}$ dan $140 \mathrm{~F}$, memasukkan sampel masing-masing fraksi gasoil 168, 288 dan 462 ke dalam tabung kapiler E899 dengan memvakumkan sampai batas yang ditentukan, merendam tabung kapiler ke dalam bak pemanas selama 15 menit, dengan stopwatch pada saat sampel tabung kapiler tersebut berada dibatas tera atas, kemudian menunggu waktu sampai batas tera bawah. Ulangi kembali dengan bak pemanas suhu $122 \mathrm{~F}$ dan $140 \mathrm{~F}$, mencatat kecepatan waktu simplo dan duplo kemudian mengalihkan dengan costantanya.

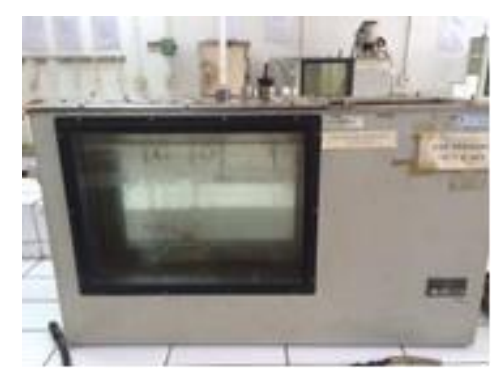

Tabel 4. Data fraksi gasoil potongan $180-350^{\circ} \mathrm{C}$ nomer sampel 168

\begin{tabular}{|l|c|c|c|}
\hline Fraksi gasoil 168 & $100^{\circ} \mathbf{F}$ & $122^{\circ} \mathbf{F}$ & $140^{\circ} \mathbf{F}$ \\
\hline Size / no. tube & $75 / \mathrm{E} 899$ & $75 / \mathrm{E} 899$ & $50 / \mathrm{E} 899$ \\
t rata - rata & 140,747 & 106,77 & 86,957 \\
E Correction & 0,035 & 0,062 & 0,099 \\
KineticViscosity (Cst) & 4,9249 & 3,71401 & 2,90798 \\
Dilaporkan & 4,925 & 3,714 & 2,908 \\
\hline
\end{tabular}

Gambar 5. Kinematic Viscosity Bath at $100^{\circ} \mathrm{F}$

Dilakukan hal yang sama untuk sampel 288 dan 462.

\section{HASIL DAN PEMBAHASAN}

Pengujian sifat fisika merupakan pengujian awal yang sangat penting untuk mengetahui informasi mengenai dasar bukan saja mengenai dasar dan sifat umum crude oil, tetapi untuk fraksi-fraksinya seperti gasoil, sehingga dapat di pastikan bagaimana cara penanganan dalam pemompaan, transportasi, penyimpanan dan impurities yang terkandung di dalam fraksi gasoil tersebut

\subsection{DATA HASIL PENGAMATAN SIFAT FISIKA FRAKSI GASOIL}

Tabel 5 Hasil pengamatan sifat fisika fraksi gasoil sampel 168

\begin{tabular}{|c|c|c|c|c|c|}
\hline No. & Parameter & Satuan & $180-350$ & $250-350$ & Metode \\
\hline 1. & Specific gravitu at $60 / 60^{\circ} \mathrm{F}$ & - & 0,9009 & 0,9345 & ASTM \\
\hline 2. & API Gravity at $60^{\circ} \mathrm{F}$ & - & 25,56 & 19,92 & D. 4052 \\
\hline 3. & Kinematic Viscosity at $100^{\circ} \mathrm{F}$ & $\mathrm{CSt}$ & 4,925 & 6,242 & \multirow{3}{*}{$\begin{array}{c}\text { ASTM } \\
\text { D. } 445-11 a\end{array}$} \\
\hline 4. & Kinematic Viscosity at $122^{\circ} \mathrm{F}$ & $\mathrm{cSt}$ & 3,714 & 4,493 & \\
\hline 5. & Kinematic Viscosity at $140^{\circ} \mathrm{F}$ & cSt & 2,908 & 3,573 & \\
\hline 6. & Pour point & ${ }^{\circ} \mathrm{C}$ & $\begin{array}{c}\text { Below } \\
\text { Minus } 36\end{array}$ & $\begin{array}{c}\text { Below Minus } \\
36\end{array}$ & $\begin{array}{l}\text { ASTM. } \\
\text { D97 }\end{array}$ \\
\hline 7. & Flash point "PMCC" & ${ }^{\circ} \mathrm{C}$ & 90.5 & 126,5 & $\begin{array}{l}\text { ASTM. } \\
\text { D93 }\end{array}$ \\
\hline 8. & ASTM Colour & & 11.0 & 11.0 & $\begin{array}{c}\text { ASTMD } \\
1500\end{array}$ \\
\hline 9 & Aniline Point & Psi & 44,4 & 43,3 & $\begin{array}{l}\text { ASTM } \\
\text { D611 }\end{array}$ \\
\hline 10. & Calculated Cetane Index & $\%$ Vol & 34,4 & 33.6 & $\begin{array}{c}\text { ASTM } \\
\text { D. } 4007-11\end{array}$ \\
\hline
\end{tabular}


Tabel 6. Hasil Pengamatan sifat fisika fraksi gasoil sampel 288

\begin{tabular}{|c|c|c|c|c|c|}
\hline No. & Parameter & Satuan & $\mathbf{1 8 0 - 3 5 0}$ & $\mathbf{2 5 0 - 3 5 0}$ & Metode \\
\hline 1. & Specific gravitu at $60 / 60^{\circ} \mathrm{F}$ & - & 0.8512 & 0,8520 & ASTM \\
D. 4052
\end{tabular}

\begin{tabular}{|c|c|c|c|c|c|}
\hline 1. & 5ecithe grativat $6060 \%$ & - & 0,3502 & 0.8331 & KSTM D.4052 \\
\hline 2 & A91 Geavity at $60 \%$ & $\cdot$ & 35,4 & 34,0 & \\
\hline 3. & Kinematic Viscosity ar $160 \%$ & cSt & 3,435 & $4.12 !$ & \multirow{3}{*}{$\begin{array}{c}\text { ASTM } \\
\text { D. } 445-11 \mathrm{a}\end{array}$} \\
\hline 14 & Xirematic hiscosity ar ILY & हst & 2,734 & 3239 & \\
\hline 5 & Revenaric Viseosigy at $140 \mathrm{C}^{\prime}$ & est & 2,332 & 2,748 & \\
\hline 6. & Pow point & $\bar{C}$ & Matas 3 & 3 & $\begin{array}{l}\text { ASIA } \\
\text { D9? }\end{array}$ \\
\hline 7. & Flash noikt PXCC & एह & 72.0 & 95.2 & $\begin{array}{l}\text { ASDS } \\
\text { D93 }\end{array}$ \\
\hline 3 & Axiline PODE & Pii & 675 & 723 & $\begin{array}{l}\text { ASDI } \\
\text { D.611 }\end{array}$ \\
\hline 9 & Calculated Crand Mdex & \%vol & 48,7 & 49,2 & $\begin{array}{c}\text { ASTI } \\
\text { D. } 4007.11\end{array}$ \\
\hline 10. & AsndColour & & 10 & 210 & $\begin{array}{l}\text { AStLS } \\
\text { D } 1500\end{array}$ \\
\hline
\end{tabular}

Tabel 7. Hasil Pengamatan sifat fisika sampel gasoil sampel 462

\subsection{ANALISA HASIL PENGAMATAN}

Data diambil dari crude oil nomor sampel 168, 288, dan 462. Dari crude oil tersebut dipisahkan berdasarkan titik didihnya dengan cara distilasi True Boiling Point (TBP). Dari distilasi TBP tersebut dapat menghasilkan fraksi gasoil seperti di bawah ini.

Tabel 8. Hasil Fraksi Gasoil dalam Crude oil

\begin{tabular}{|l|r|r|r|}
\hline & 168 & 288 & 462 \\
\hline Yield on Crude Oil (\% wt) & 48,5 & 9,8 & 84,9 \\
\hline
\end{tabular}

Berdasarkan tabel diatas sampel 168 sebanyak 48,5\% dari crude oil tersebut merupakan fraksi gasoil, dan specific gravity dari crude oil ini sebesar 0,9510 yang mana masuk dalam klasifikasi heavy crude oil, pada crude oil nomor sampel 462 hanya 84,9\% dari crude oil tersebut merupakan fraksi gasoil dan specific gravity crude oil ini sebesar 0,8644, dimana masuk ke dalam klasifikasi medium crude oil. Sedangkan pada sampel nomor 288 hanya 9,8 dari crude oil tersebut merupakan fraksi gasoil dan specific gravity crude oil ini sebesar 0,7162, dimana masuk ke dalam klasifikasi light crude oil. Pada crude oil sampel nomor 288 hanya sedikit sekali mendapatkan fraksi gasoil, Maka semakin ringan jenis crude oil nya, maka akan semakin sedikit mendapatkan fraksi gasoil nya.

\subsubsection{SPECIFIC GRAVITY AT 60/60 F (ASTM D. 4052) DAN API GRAVITY AT 60 F (BY CONVERSION)}

Specific gravity merupakan perbandingan sejumlah volume zat pada temperatur tertentu terhadap massa air murni dengan volume yang sama pada temperatur yang sama atau temperatur yang berbeda. Kedua temperatur acuan harus dinyatakan secara eksplisit. API gravity merupakan standar khusus dari specific gravity. berdasarkan hasil pengamatan 
Tabel 5, Tabel 6 dan tabel 7 semakin besar Specific Gravity suatu sampel maka semakin kecil nilai API Gravity. semakin besar Specific Gravity maka semakin kental fraksinya.

\subsubsection{KINEMATIC VISCOSITY (ASTM D. 445-11A)}

Bertujuan untuk menguji kekentalan kinematik dari fraksi yang mudah mengalir ataupun tidak. Dapat kita ketahui dari data diatas sampel 168 potongan 180-350 dan 250-350 memiliki nilai viscosity yang paling tinggi, hal ini menunjukkan bahwa sampel tersebut mengandung fraksi berat dan diperlukan suhu yang tinggi untuk mengalirkannya. Sedangkan pada sampel 288 memiliki nilai viscosity yang paling rendah, hal ini menunjukkan bahwa sampel tersebut banyak mengandung fraksi ringan. Pengujian ini sangat berguna untuk memperkirakan transportasi minyak mentah atau crude oil yang dialirkan dari sumur produksi menuju stasiun pengumpul agar tidak terjadi pembekuan pada pipeline.

\subsubsection{POUR POINT (ASTM D.5853 -11)}

Berdasarkan Tabel 5 Sampel 168 memiliki suhu rendah. Suhu dan titik tuang berbanding terbalik, maka sampel tersebut memiliki titik tuang tinggi, hal ini menunjukkan bahwa sampel 168 tersebut cenderung encer atau memiliki fraksi ringan yang lebih banyak dan kandungan lilinnya rendah. Pada Tabel 7 Sampel 462 memiliki suhu tinggi. Suhu dan titik tuang berbanding terbalik, sampel tersebut memiliki titik tuang rendah, hal ini menunjukkan bahwa sampel 462 tersebut cenderung mudah membeku atau memiliki fraksi ringan yang lebih banyak,kandungan lilinnya rendah.

\subsubsection{FLASH POINT "PMCC" (IP. 170)}

Flash point merupakan titik nyala pada suhu terendah dimana uap gasoil dalam campurannya dengan udara akan menyala jika dikenai nyala uji pada kondisi tertentu. Suhu flash point "PMCC" lebih dari $78^{\circ} \mathrm{C}$ sampai $2{ }^{\circ} \mathrm{C}$, berdasarkan Tabel 6 . Nilai flash point menunjukkan bahwa sampel 168 potongan 180-350 ini masih banyak terdapat fraksi ringanya.

\subsubsection{CALCULATED CETANE INDEX}

Berdasarkan hasil hitungan calculated cetane index pada sampel 168, 288 dan 462 dengan potongan 180-350 dan temperatur 250-350. hasil pengamatan pada tabel 5,6,7 sampel 462 memiliki estimasi angka anti ketuk besar diantarasampel 168 dan 288.

\subsubsection{ANILINE POINT} dan contoh.

Titik Anilin merupakan temperatur minimum pencampuran seimbang untuk volume yang seimbang antara anilin

\subsubsection{ASTM COLOUR}

Pada uji ASTM Colour kita dapat membandingkan warna standar dengan warna sampel. Untuk menentukan warna dasar fraksi gasoil. Untuk mengetahui spesifikasi produk ke perusahaan. Berdasarkan pengamatan uji ASTM Colour pada sampel 168 mempunyai warna yaitu L 1,0 artinya warna tersebut masuk kedalam kecerahan di nomer 1,0. Pada sampel 288 mempunyai warna yaitu L 1,0 warna tersebut masuk kecerahan di nomer 1,0. Pada sampel 462 memiliki warna yaitu L 1,0 warna tersebut masih standar di gasoil.

\section{KESIMPULAN}

Berdasarkan hasil analisa pada pengujian sifat fisika Gasoil adalah Specific gravity at $60 / 60{ }^{\circ} \mathrm{C}$, API Gravity at $60{ }^{\circ} \mathrm{F}$, Kinematic Viscosity, Pour Point, Flash Point "PMCC",Aniline Point, ASTM Colour, ASTMD-86, Calculated Cetane Index.

1 Specific Gravity at $60 / 60^{\circ} \mathrm{F}$ dan API Gravity at $60^{\circ} \mathrm{F}$ (By Conversion) dapat di ketahui bahwa sampel 168 termasuk dalam klasifikasi heavy crude oil (fraksi berat), sampel 288 termasuk dalam klasifikasi light crude oil (fraksi ringan), sampel 462 termasuk dalam klasifikasi medium crude oil. Pada Kinematic viscosity, dapat di ketahui bahwa sampel 462 termasuk dalam gasoil yang sedang, tidak kental dan tidak juga cair. dibandingkan dengan sampel 288 dan sampel 168.

2 Pada Pour Point, dapat diketahui bahwa sampel 462 memiliki titik tuang yang rendah dibandingkan dengan sampel 168 dan sampel 288.

3 Pada Flash Point "PMCC", dapat diketahui bahwa sampel 462 yang mudah menyala di suhu rendah

4 Pada Calculated Cetane Index, dapat diketahui bahwa sampel 462 memiliki estimasi angka anti ketuk paling besar dibandingkan dengan sampel lainnya.

5 Pada Aniline Point, diketahui bahwa sampel 462 memiliki pencampuran seimbang untuk volume yang seimbang antara aniline dan sampelnya.

6 Dan ASTM Colour, dapat diketahui bahwa ketiga sampel tersebut memiliki warna yang sama yaitu Light 1,0.

\section{DAFTAR PUSTAKA}

[1] A. Hardjono, Teknologi Minyak Bumi. Yogyakarta: Universitas Gajah Mada, 2001.

[2] S. Kardjono, "Proses Pengolahan Minyak dan Gas Bumi." 
[3] American Society for Testing and Materials ASTM D-4052-11., Standard Test Methode for Distilation of Petroleum Products at Atmospheric Pressure. Philadekphia: ASTM International.

[4] A.-A. S. for T. Materials, Standard Test for Distillation of Petroleum Products at Atmospheric Pressure. ASTM D86. West Conshohocken, Pa, 2012.

[5] A. S. for T. and M. A. D-4052, Standard Test Methode for ASTM Colour of Petroleum Products (ASTM Colour Scale). Philadelphia: ASTM International, 2007. 